\title{
Caracterização citomorfológica, cultural, molecular e patogênica de Rhizoctonia solani Kühn associado ao arroz em Tocantins, Brasil
}

\author{
Elaine Costa Souza ${ }^{1,2}$, Eiko Eurya Kuramae ${ }^{3}$, Andreia Kazumi Nakatani ${ }^{4}$, \\ Marco Antonio Basseto ${ }^{1}$, Anne Sitarana Prabhu ${ }^{5}$, Paulo Cezar Ceresini ${ }^{1,6}$
}

${ }^{1}$ UNESP - Campus de Ilha Solteira, Dept. Fitoss., Eng. Rural e Solos, CP 31, CEP 15385-000, Ilha Solteira, SP; ${ }^{2}$ UFMS - Centro Universitário de Três Lagoas, voluntária da UNESP; aluna do Programa de Pós- Graduação em Agronomia; ${ }^{3}$ Centraalbureau voor Shimimmelcultures (CBS) Fungal Biodiversity Center - Institute of the Royal Netherlands Academy of Arts and Sciences, Utrecht, The Netherlands; ${ }^{4} \mathrm{CAPTA}$ - Citros Sylvio Moreira, Cordeirópolis, São Paulo; ${ }^{5}$ EMBRAPA Arroz e Feijão, Santo Antonio de Goiás, GO; ${ }^{6}$ Swiss Federal Institute of Technology ETHZ, Institute of Integrative Biology, LFW B28, 8092 Zurich, Switzerland, e-mail: paulo.ceresini@agrl.ethz.ch

Autor para correspondência: Paulo Cezar Ceresini

Data de chegada: 30/07/2004. Aceito para publicação em: 10/07/2006.

1101

\section{RESUMO}

Souza, E.C., Kuramae, E.E., Nakatani A.K., Basseto, M.A., Prabhu, A.S., Ceresini, P.C. Caracterização citomorfológica, cultural, molecular e patogênica de Rhizoctonia solani Kühn associado ao arroz em Tocantins, Brasil. Summa Phytopathologica, v.33, n.2, p.129-136, 2007.

No Estado do Tocantins, no Norte do Brasil, a incidência de rizoctoniose no arroz é importante, causando danos significativos em lavouras de arroz irrigado. O principal objetivo deste trabalho foi determinar o grupo de anastomose (AG) de isolados de $R$. solani associados ao arroz naquela região, testando a hipótese de que esses isolados pertencem ao grupo padrão de anastomose AG-1 IA, que também é o agente causal da mela em soja em áreas úmidas do Norte do Brasil. Todos os quatro isolados de arroz foram caracterizados, através de fusão de hifas, como AG-1 IA. A caracterização cultural, em função das temperaturas basais (mínimas, máximas e ótimas), evidenciou que os isolados de $R$. solani de arroz apresentaram perfis semelhantes aos padrões AG-1 IA, AG-1 IB e AG-1 IC. Os isolados de arroz foram caracterizados como autotróficos para tiamina assim como os isolados padrões AG-1 IA, IB, IC, AG-4 HGI e o isolado da mela da soja. O teste de patogenicidade em plantas de arroz cultivar IRGA-409 e de patogenicidade cruzada à cultivar IAC-18 de soja (suscetível à mela), indicou que além de causar a queima da bainha em arroz, esses isolados causam mela em soja. Da mesma forma, o isolado SJ-047 foi patogênico ao arroz. As seqüências de bases de DNA da região ITS-5.8S do rDNA dos isolados do arroz foram similares às seqüências do AG-1 IA, depositadas no GenBank - NCBI. A filogenia do ITS-rDNA indicou um grupo filogenético comum formado pelos isolados do arroz, o isolado da soja e o isolado teste do AG-1 IA. Assim, com base em características citomorfológicas, culturais, filogenéticas e patogênicas, foi confirmada a hipótese de que os isolados de $R$. solani patógenos de arroz do Estado do Tocantins pertencem ao grupo de anastomose AG-1 IA, além da indicação de que esses isolados podem também causar a mela em soja.

Palavras-chave adicionais: grupos de anastomose,Patogenidade cruzada, soja, filogenia, DNA ribossomal

\begin{abstract}
In Tocantins State, Northern Brazil, the incidence of Rhizoctonia sheath blight on rice is important, causing significant yield losses on rice crops under irrigation. The main objective of this research was to determine the anastomosis group (AG) of $R$. solani associated with rice in that area, testing the hypothesis that these isolates are from the AG$1 \mathrm{IA}$, which is also associated with the soybean leaf blight occurring in wet areas of Northern Brazil. All the four rice isolates were characterized, by hyphal fusion, as AG-1 IA. By cultural characterization, based on basal temperatures for mycelial growth (minimum, optimum and maximum), the rice isolates had growth profile similar to the tester isolates AG-1 IA, AG-1 IB and AG-1 IC. The rice isolates were characterized as autotrophic for thiamine, as well as the AG testers AG-1 IA, IB, IC, AG-4 HGI and the soybean leaf
\end{abstract}

ABSTRACT

Souza, E.C., Kuramae, E.E., Nakatani A.K., Basseto, M.A., Prabhu, A.S., Ceresini, P.C. Citomorphological, cultural, molecular and pathogenical characterization of Rhizoctonia solani Kühn associated with rice in Tocantins, Brazil. Summa Phytopathologica, v.33, n.2, p.129-136, 2007.

blight isolate SJ-047. The pathogenicity test on rice IRGA-409 and the cross pathogenicity on soybean IAC-18 (susceptible to the leaf blight disease) indicated that, besides causing sheath blight, these rice isolates also cause leaf blight on soybean. Similarly, the soybean isolates SJ-047 was pathogenic to rice. The sequences from the ITS$5.8 \mathrm{~S}$ region of rDNA from the rice isolates were similar to sequences of AG-1 IA deposited at GenBank ${ }^{\circledR}$ - NCBI. The ITS-rDNA phylogeny indicated a common phylogenetic group formed by these rice isolates, the isolate SJ-047 and the tester AG-1 IA. Thus, based on cytomorphological, cultural, phylogenetics and pathogenic attributes, the hypothesis that the rice isolates of $R$. solani from Tocantins all belong to the AG-1 IA was confirmed, besides the indication that these isolates can also cause soybean foliar blight.

Additional keywords: anastomosis groups, cross-pathogenicity, soybean, phylogeny, ribossomal DNA. 
No Brasil, a ocorrência da queima-da-bainha vem causando danos significativos na produtividade de arroz irrigado (Oryza sativa L.), principalmente em Formoso do Araguaia, no Estado de Tocantins (TO), onde foi constatada a doença em lavouras de arroz desde a implantação dos projetos cooperativos, ainda que com baixa incidência (32).

A queima-da-bainha ou rizoctoniose, causada pelo fungo Rhizoctonia solani Kuhn, foi identificada pela primeira vez em lavouras de arroz de alguns municípios do Estado de São Paulo, em 1967 (3). A incidência desta doença também foi observada no Rio Grande do Sul após a introdução de cultivares norte-americanas $(11,33)$, e no Estado do Amazonas (35). Ao longo dos anos, tem aumentado a densidade do inóculo do patógeno no solo em rotação ou sucessão com a cultura de soja (Glycine max L.), uma vez que ambos hospedeiros são suscetíveis a $R$. solani $(16,17)$.

Os danos causados por $R$. solani a cultivares de arroz são a queima da bainha e colmos, caracterizadas por manchas ovais, elípticas e bordas marrons bem definidas nos tecidos afetados. Em casos mais severos, observa-se manchas semelhantes nas folhas inferiores resultando em seca parcial ou total, e esterilidade de algumas espiguetas, ocasionando inclusive a morte da planta (25). O período crítico de incidência ocorre entre o perfilhamento e a floração $(5,11)$. Atualmente, a rizoctoniose ocorre em todas as lavouras de arroz irrigado, em menor ou maior grau de severidade no Estado do Tocantins, com aproximadamente 70 mil ha. plantados em rotação com a soja (32).

Com relação ao gênero Rhizoctonia, este divide-se em espécies com hifas binucleadas como $R$. callae, $R$. cerealis, $R$. endophytica, $R$. fragariae, $R$. fumigata, $R$. ramicola, $R$. oryzae-sativae, $R$. repens, $R$. anaticula e espécies com hifas multinucleadas como $R$. zeae, $R$. oryzae e $R$. solani (a espécie mais importante do gênero, como fitopatógeno) (36).

R. solani é um fungo habitante do solo que tem como forma sexuada Thanatephorus cucumeris (Frank), pertencente ao Filo Basidiomycota. A anamorfase (ou estágio assexual) $R$. solani ocorre mundialmente causando doenças em uma ampla variedade de plantas cultivadas (1, 4, 36). Ao contrário do que se postulava no passado a respeito da condição de patógeno polífago, a gama de hospedeiros de cada um dos grupos de anastomose de $R$. solani é restrita. Cada grupo de anastomose está freqüentemente associado a determinado hospedeiro ou a um grupo restrito de hospedeiros $(4,28,36)$.

De acordo com conceitos atuais, $R$. solani é uma espécie complexa composta por pelo menos 14 grupos (e diversos subgrupos): AG-1 a 13 e AG-BI $(8,14,29,36)$. Baseando-se na ocorrência de fusão de hifas (anastomose) com isolados padrões (AGs), isolados pertencentes ao mesmo AG têm as hifas atraídas e fundidas umas as outras, enquanto hifas de isolados de $\mathrm{AG}$ diferentes não são capazes de se fundirem entre si (7).

O conceito sobre grupo de anastomose dentro do complexo $R$. solani é de extrema importância para fitopatologistas e melhoristas de plantas, sob o ponto de vista etiológico. Cada grupo (ou subgrupo) de anastomose é considerado uma espécie distinta sobre o ponto de vista filogenético $(18,41)$. Assim, outro critério importante utilizado na identificação de grupos de anastomose de $R$. solani é a similaridade de bases da região ITS do $\operatorname{rDNA}(7,18)$.

Para se complementar o processo de identificação, recomenda-se caracterizar atributos culturais considerados particulares aos grupos de anastomose, tais como a necessidade de tiamina para o crescimento micelial, a temperatura ótima de crescimento, o tipo de escleródio formado, o perfil isoenzimático, padrões de RFLP, entre outros ( 9 , $21,23,24,27)$.
Apesar da importância da rizoctoniose do arroz no Tocantins, ainda não há informação quanto ao grupamento de anastomose de $R$. solani associado ao arroz. Enquanto não se esclarecer esta questão ligada à etiologia do patógeno, não há como dar suporte a um programa de melhoramento para resistência de cultivares comerciais de arroz à $R$. solani. Sob o ponto de vista de manejo da cultura, é importante determinar a patogenicidade cruzada destes isolados de $R$. solani à soja, uma vez que há relatos do patógeno afetando as duas culturas na região.

Dessa forma, os objetivos deste trabalho compreenderam a identificação do grupo de anastomose de isolados de $R$. solani associados ao arroz através de análise citomorfológica, seqüênciamento de bases do rDNA, e caracterização cultural baseada na determinação de temperaturas basais (mínima, ótima e máxima), necessidade de tiamina para o crescimento micelial. Testou-se, também, a patogenicidade desses isolados de arroz a plantas de soja.

\section{MATERIAL E MÉTODOS}

\section{Caracterização de isolados de Rhizoctonia solani com relação} ao grupamento de anastomose.

Os isolados de $R$ solani causadores da queima da bainha em arroz foram cedidos pela EMBRAPA - Arroz e Feijão e o isolado de SJ-047, de soja, pelo Dr. Nilton L. Souza da UNESP - Campus de Botucatu (Tabela 1). O isolado de $R$. solani representante do grupo de anastomose AG-1 IA foi pareado com os isolados de $R$. solani associados ao arroz. A anastomose das hifas foi determinada pela técnica da lâmina de vidro para microscopia contendo uma fina camada de meio agar-água (AA) a 3\% e 1,5 mL de corante para alimento McCormick $(19,20)$. Os isolados de R. solani do arroz (Rhs-3F1, Rhs-3F6, Rhs-4F1 e Rhs-9F1) e o isolado padrão AG-1 IA foram incubados em BDA+estreptomicina $\left(0,050 \mathrm{~g} \cdot \mathrm{L}^{-1}\right)$ por $48 \mathrm{~h}$ em estufa biológica, onde um disco foi retirado das margens da cultura de BDA. Esses foram posicionados a $2 \mathrm{~cm}$ um do outro sobre lâmina de vidro contendo o meio acima citado. O conjunto foi incubado por $18 \mathrm{~h}$ em placas de petri, com 3 repetições de cada isolado. As lâminas foram observadas em microscópio utilizando uma gota de $\mathrm{H}_{2} \mathrm{O}$ sobrepondo-se uma lamínula de vidro.

\section{Seqüênciamento de bases de DNA}

A extração de DNA, a amplificação via PCR e o seqüênciamento foram realizado no Laboratório de Fitopatologia do Departamento de Produção Vegetal da Faculdade de Ciências Agronômicas, Campus de Botucatu, UNESP. Estes isolados foram incubados em meio de BDA (batata-dextrose-agar suplementado com estreptomicina a $0,050 \mathrm{~g} / \mathrm{L}$ ), e mantidos por 8 dias em estufa biológica a $25^{\circ} \mathrm{C}$, e transferido para o meio de BD (batata-dextrose suplementado com estreptomicina). $\mathrm{O}$ micélio foi recuperado por filtração em filtro de papel Whatman, macerado em nitrogênio líquido e o DNA genômico total extraído de acordo com Kuramae-Izioka (22). A amplificação por PCR seqüênciamento da região ITS1-5.8S-ITS2 rDNA foi realizada segundo Fenille et al. (13) em termociclador marca PTC-100. Os produtos de PCR foram purificados usando-se coluna de MicroSpin S-400 (Amershan Pharmacia). Para seqüênciamento da região ITS do rDNA, foi utilizado o kit pré-preparado para ciclo de seqüênciamento baseado em química de corante terminador ("dye terminator cycle sequencing pre-mix kit") (Amershan Pharmacia). Setenta e cinco ng de DNA amplificados foram utilizados por reação e um $\mu \mathrm{M}$ de cada um dos iniciadores ITS2, ITS3, ITS4 ou ITS5 em reações independentes. Os produtos de seqüênciamento foram separados em gel de poliacrilamida 
Tabela 1. Relação de isolados testes de grupos de anastomose de Rhizoctonia solani usados neste estudo para testar o grupamento de anastomose de isolados de Rhizoctonia solani, associados a queima-da-bainha do arroz e mantidos na micoteca do Laboratório de Fitopatologia do Departamento de Fitossanidade da UNESP Campus de Ilha Solteira.

\begin{tabular}{|c|c|c|c|c|c|c|}
\hline \multirow{3}{*}{$\begin{array}{l}0 \\
0 \\
0 \\
0 \\
0 \\
0 \\
0 \\
0 \\
0 \\
0 \\
0 \\
0 \\
0 \\
0 \\
0 \\
0\end{array}$} & AG-1 IA & H5-526 & Milho & Tohoku, Japão & 1993 & AY154301 \\
\hline & AG-1 IB & - & Alface & Ohio, EUA & 1993 & AY154302 \\
\hline & AG-2.2 IV & RI-64 & Beterraba & Ohio, EUA & 1993 & AY270014 \\
\hline \multirow{3}{*}{ 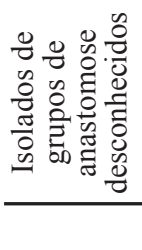 } & - & Rhs-3F1 & Arroz "Epagri 108" & Lagoa de Confusão, TO & 1998 & - \\
\hline & - & Rhs-3F6 & Arroz "Rio Formoso" & “ & “ & - \\
\hline & - & Rhs-9F1 & Arroz "Epagri 108” & “ & “ & - \\
\hline
\end{tabular}

a 6\%, utilizando-se seqüenciador automático PE Applied Biosystems ABI-377. As seqüências obtidas foram analisadas pelo programa Phred/ Phrap/Consed para determinação de qualidade (15), alinhadas pelo programa computacional ClustalW (40) e comparadas com seqüências da região ITS do rDNA de todos os grupos de anastomose de R. solani e Rhizoctonia spp. binucleadas depositadas no banco de dados GenBank ${ }^{\circledR}$ do NCBI (National Center for Biotechnology Information, Bethesda, MD, EUA). Essas comparações entre seqüências similares foram efetuadas pela ferramenta BLASTN (nucleotídeo-nucleotídeo) versão 2.2.6, de 09/04/2003, disponível no “site" http:// www.ncbi.nih.gov/BLAST (2).

Estabelecimento de curvas de crescimento micelial radial em função da temperatura

O estabelecimento de curvas de crescimento micelial radial dos quatro isolados de $R$. solani associados ao arroz e o de soja, em função da temperatura, foi efetuado para determinação das temperaturas basais (mínima, ótima e máxima). Os isolados do fungo foram cultivados por 48 horas em placas de petri de $90 \mathrm{~mm}$ de diâmetro contendo meio de cultura de BDA suplementado com $0,005 \mathrm{~g} . \mathrm{L}^{-1}$ de cloranfenicol e $0,005 \mathrm{~g} \cdot \mathrm{L}^{-1}$ de estreptomicina (BDACE), em estufa biológica a 10, 15, $20,25,30,35$ e $40^{\circ} \mathrm{C}$, no escuro. O inóculo foi constituído de um disco de micélio de $7 \mathrm{~mm}$ de diâmetro obtidos das margens de culturas crescidas em BDACE a $25^{\circ} \mathrm{C} / 48 \mathrm{~h}$, sob mesma condição de luz. Os isolados de $R$. solani utilizados como padrões foram AG-1 IA, AG1 IB, AG-1 IC (Tabela 1). As comparações foram efetuadas determinando-se o crescimento micelial radial dos isolados $(\mathrm{mm} / \mathrm{dia})$ em cada temperatura $\left({ }^{\circ} \mathrm{C}\right)$. $\mathrm{O}$ experimento foi delineado de forma inteiramente casualizada contendo 5 repetições. Repetiu-se este experimento duas vezes.

\section{Necessidade de tiamina para o crescimento micelial}

Para a determinação da necessidade de tiamina para o crescimento micelial dos isolados de $R$. solani do arroz e isolados padrões de AGs, utilizou-se de meio GASP descrito por Ogoshi \& Ui (27). Discos tirados de culturas de isolados de $R$. solani associadas ao arroz, e os isolados padrões foram incubados em BDA + estreptomicina $\left(0,050 \mathrm{~g} . \mathrm{L}^{-}\right.$ $\left.{ }^{1}\right)$ a $25^{\circ} \mathrm{C} / 48 \mathrm{~h}$ em estufa biológica sob ausência de luz, e depois transferidos para meio GASP+20 g de agar [GASP sólido (com pH corrigido de 4,7 para 7)], sem tiamina e incubados em estufa biológica a $25^{\circ} \mathrm{C} / 10$ dias sob ausência de luz. Um disco de cultura de cada isolado crescido em meio GASP sólido foi retirado e transferido para $50 \mathrm{~mL}$ de meio GASP líquido em frascos de erlenmeyer de $250 \mathrm{~mL}$ com tiamina e sem tiamina. Os frascos foram distribuídos em um agitador horizontal e incubados por 19 dias no escuro. Determinou-se a massa micelial acumulada para cada isolado após secagem em estufa a $65^{\circ} \mathrm{C} / 48 \mathrm{~h}$. Os isolados padrões AG-1 IA, IB, IC, AG-4 HGI (autotróficos para tiamina) e o AG-2-2 IV (auxotrófico) (36), foram comparados com os isolados do arroz Rhs-3F1, Rhs-3F6, Rhs-4F1, Rhs-9F1 e com o isolado de soja SJ-047. O experimento foi delineado de forma inteiramente casualizada, com 5 repetições. Este experimento foi repetido duas vezes.

\section{Teste de patogenicidade cruzada}

O teste de patogenicidade cruzada foi realizado em casa de vegetação no Campus da UNESP de Ilha Solteira - CISA. O solo utilizado foi retirado de uma área não cultivada na Fazenda de Ensino de Pesquisa do CISA. Cada vaso utilizado continha $1.500 \mathrm{~g}$ de solo. Para o teste de patogenicidade com plantas de soja, a semeadura do experimento foi realizada dia 13/11/2003, utilizando cerca de 15 sementes por vaso. $\mathrm{O}$ desbaste foi realizado sete dias após a semeadura deixando-se cinco plantas de soja por vaso. Os vasos foram irrigados, com auxílio de uma proveta, utilizando-se água destilada e deionizada em quantidades pré-determinadas. Após cultivo em meio de $\mathrm{BDA}$ a $25^{\circ} \mathrm{C} / 5$ dias, o inóculo do patógeno foi preparado para cada um dos cinco isolados de $R$. solani testados triturando-se o meio em liquidificador, por 30 segundos, com água destilada na proporção de $100 \mathrm{~mL} /$ placa. O preparo do inóculo e a inoculação foram efetuados de acordo com metodologia proposta por Meyer (26) para avaliação da reação da mela na soja. A inoculação foi realizada através de pulverização de suspensão de fragmentos de micélio e escleródios, com auxílio de um pulverizador manual, no dia 10/12/2003. A variedade de soja usada nesse experimento foi a IAC -18 , suscetível à mela (26). A severidade da doença foi avaliada cinco dias após a inoculação, sendo coletada uma folha por planta (totalizando cinco folhas por vaso). As folhas foram fotografadas utilizando-se uma câmara digital Sony modelo DSC-F505V, 
para se determinar a área foliar infectada. As plantas de cada vaso foram coletadas e secas em estufa a $65^{\circ} \mathrm{C} / 48 \mathrm{~h}$, e em seguida pesadas para determinação da matéria seca.

Para o teste de patogenicidade em plantas de arroz, usou-se as mesmas condições empregadas para o cultivo das plantas de soja. A semeadura do experimento foi feita no dia $03 / 12 / 2003$, sendo o desbaste realizado sete dias após a semeadura, deixando-se cinco plantas de arroz por vaso. O preparo do inóculo foi feito em meio de $\mathrm{BDA}+$ estreptomicina a $25^{\circ} \mathrm{C} / 3$ dias, onde em cada placa foram colocados pedaços de palito de dente previamente autoclavados. A inoculação foi realizada no dia 15/01/04 com os palitos de dentes infestados com micélio dos fungos inseridos na bainha de cada planta de arroz. A cultivar de arroz utilizada foi a IRGA-409. A severidade da doença foi avaliada cinco dias após a inoculação, na qual as plantas foram coletadas e fotografadas com câmera digital, para se determinar o comprimento das lesões. Posteriormente, da mesma forma como o efetuado com a parte área das plantas de soja, as plantas de arroz foram coletadas e secas em estufa a $65^{\circ} \mathrm{C} / 48 \mathrm{~h}$ e depois pesadas. Os experimentos de patogenicidade a plantas de soja e de arroz foram delineados de forma casualizada, com 4 repetições.

\section{Análise dos dados}

Para determinar as relações filogenéticas, aplicou-se análise de máxima verossimilhança (MV) utilizando-se o programa PAUP* 4.0b10 (38). Para a análise de MV, MODELTEST 3.7 (30) foi utilizado para se determinar o modelo de substituição de bases de DNA o qual mais se ajustou aos dados. A análise filogenética foi executada tratando todos os 615 caracteres (bases) com o mesmo peso e considerando inserções como dados perdidos. Deste total, 48 continham sítios variáveis dentro do complexo AG-1 (IA, IB e IC). Análise de bootstrap foi executada para se testar a significância estatística para cada ramo das árvore gerada pela análise de MV, com 100 pseudo-replicações com todos os caracteres re-amostrados em cada replicação, com adição casual de seqüências dos taxa por replicação e com opção de troca de ramificações fixada como TBR.

As curvas de crescimento radial médio em função da temperatura, bem como o requerimento de tiamina para crescimento micelial, foram determinados utilizando-se a média e o desvio padrão dos valores observados. Os dados do experimento de patogenicidade cruzada à soja e ao arroz (variáveis massa seca da parte área das plantas de soja e arroz, comprimento de lesão e área foliar infectada), foram submetidos à análise de variância pelo teste $\mathrm{F}$ de Snedecor e ao teste de Tukey para comparação de médias.

\section{RESULTADOS E DISCUSSÃO}

A fusão entre hifas dos isolados Rhs-3F1, Rhs-3F6, Rhs-4F1 e Rhs-9F1 de $R$. solani do arroz com o grupo de anastomose AG-1 IA foi positiva, sendo observada fusão imperfeita entre hifas, ou reação do tipo C2 como descrito por Carling et al. (6). Observou-se, também, que as culturas desses isolados de $R$. solani do arroz, após uma semana de crescimento em meio BDACE, produzem escleródios do tipo sasakii, típicos do AG-1 IA, sendo relativamente maiores que os escleródios dos demais grupos de anastomose e, excepcionalmente, possuem parede externa escura $(25,36)$. O AG-1 IA é relatado como causador da queima da bainha em outros lugares do mundo e da mela da soja no Brasil e no Sul dos Estados Unidos (39). Alem do arroz, o AG-1 IA é também um dos patógenos mais importantes afetando outras Poaceae, como milho e sorgo, e também Fabaceae, como a soja $(12,13,26,39)$.
O seqüênciamento de bases da região ITS (ITS1-5.8S-ITS2) do rDNA, confirmou a associação dos isolados de $R$. solan $i$ associados ao arroz com o grupo de anastomose AG-1 IA. A comparação dessas seqüências com outras depositadas no banco de dados GenBank ${ }^{\circledR}$ do $\mathrm{NCBI}$, indicou similaridade com as de diversos isolados pertencentes ao grupo AG-1 IA no resto do mundo. Através da análise filogenética da região ITS do rDNA por MV, os isolados de arroz e o de soja formaram um único grupo filogenético com o grupo AG1-IA, com $98 \%$ de suporte estatístico através de análise de bootstrap (Figura 1). A região ITS do rDNA dos isolados de $R$. solani do arroz mostrou-se extremamente conservada, não tendo sido observada qualquer variação na seqüência de nucleotídeos entre estes e o AG-1 IA. Ao compará-los com o isolado SJ-047 da soja, foi observada apenas uma mutação na posição 140 (A - G) da região ITS do rDNA. Em contraste, as seqüências da região ITS-rDNA dos isolados de arroz, de soja e do isolado padrão AG-1 IA divergiram cerca de 5,1 a 5,8\% (em termos do número total de mutações, ou bases diferentes, ao longo da seqüência) em relação às seqüências da região ITS-rDNA dos grupos AG-1 IB e AG-1 IC. Esta observação corrobora informação sobre a extensão da divergência filogenética entre os grupos AG-1 IA, IB e IC (18). As seqüências dos isolados de $R$. solani do arroz serão depositadas no GenBank ${ }^{\circledR}$ - NCBI.

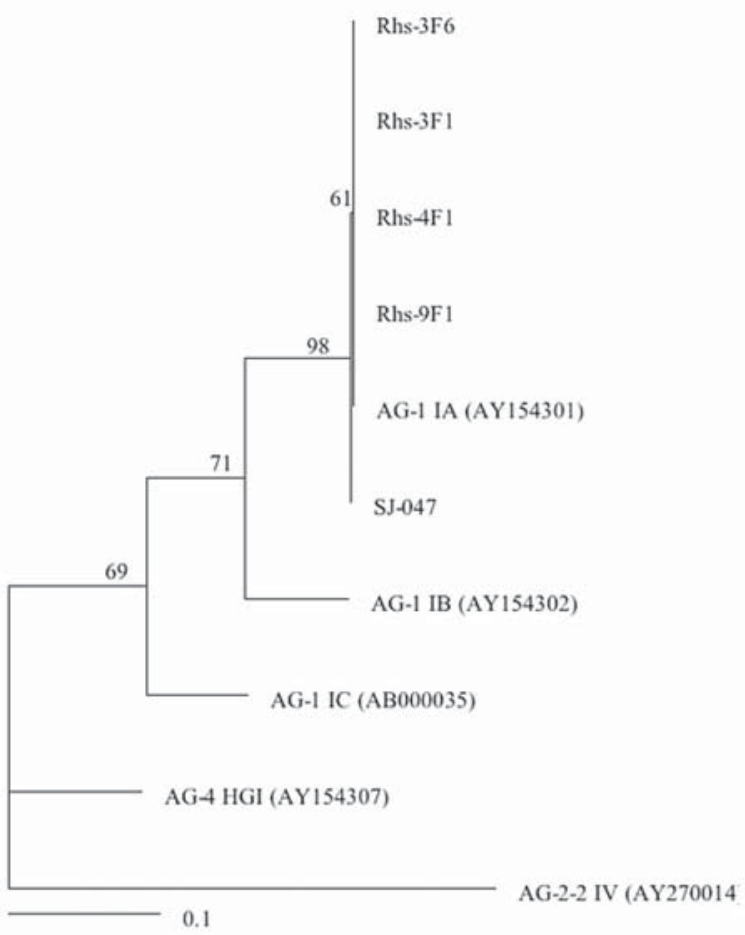

Figura 1. Árvore de máxima verossimilhança (MV) baseada no modelo TIM + I + G de evolução de bases de DNA. O valor de MV para a respectiva árvore foi de 1688,60. Ao lado de cada ramo da arvore são apresentados os valores relativos à significância estatística através de analise de "bootstrap" das árvores geradas por análise de máxima verossimilhança (MV). Estes valores são expressos em percentual relativo à 100 pseudoreplicações. Por exemplo, 98\% das 100 arvores de ML geradas por pseudoreplicações dos dados apresentaram ramo que agrupa todos os haplótipos dos isolados de Rhizoctonia solani do arroz, da soja e do AG-1 IA. As relações filogenéticas foram construídas utilizando-se seqüências de DNA da região ITS-5.8S do rDNA contendo um total de 615 pares de bases. A barra acima indica número de substituições / sítio. A árvore foi enraizada usando seqüências da região ITS do AG-2-2 IV. Os taxa são identificados pelo código do isolado e/ou o código da seqüência obtida do GenBank ${ }^{\circledR} / \mathrm{NCBI}$. A descrição dos isolados de Rhizoctonia solani é apresentada na Tabela 1. 
A amostra de isolados utilizada nesta pesquisa não é suficiente para inferir qualquer informação sobre o nível de variabilidade genética real dentro do AG-1 IA proveniente de arroz e entre populações de isolados de $R$. solani AG-1 IA de outros hospedeiros. De maneira geral, a região ITS do rDNA parece ser conservada para isolados do AG-1 IA associados a diversas culturas da família Poaceae (arroz, milho, milheto, sorgo e gramíneas invasoras de áreas cultivadas). Um único haplótipo da região ITS do rDNA do patógeno foi detectado afetando Poaceae em escala mundial (10). Entretanto, o mesmo não

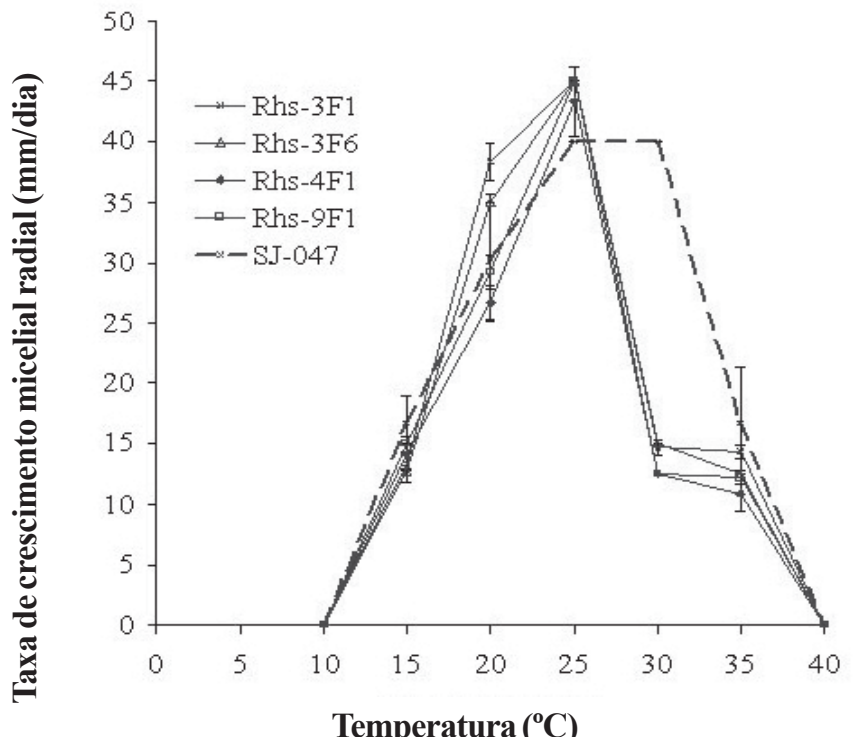

se observa quando se compara isolados de Fabaceae. Postula-se a ocorrência de dois grandes clados de haplótipos da região ITS-5.8 S do rDNA de $R$. solani AG-1 IA: o clado das Poaceae, com reduzida variabilidade genética e distribuição mundial, e o clado das Fabaceae (incluindo haplótipos de isolados da soja e do feijão) com elevada variabilidade genética e distribuição geográfica restrita ao continente Centro-Sul Americano (10).

Estas diferenças no nível de variação genética apresentada por cada um dos grupos de isolados individualmente (em função do

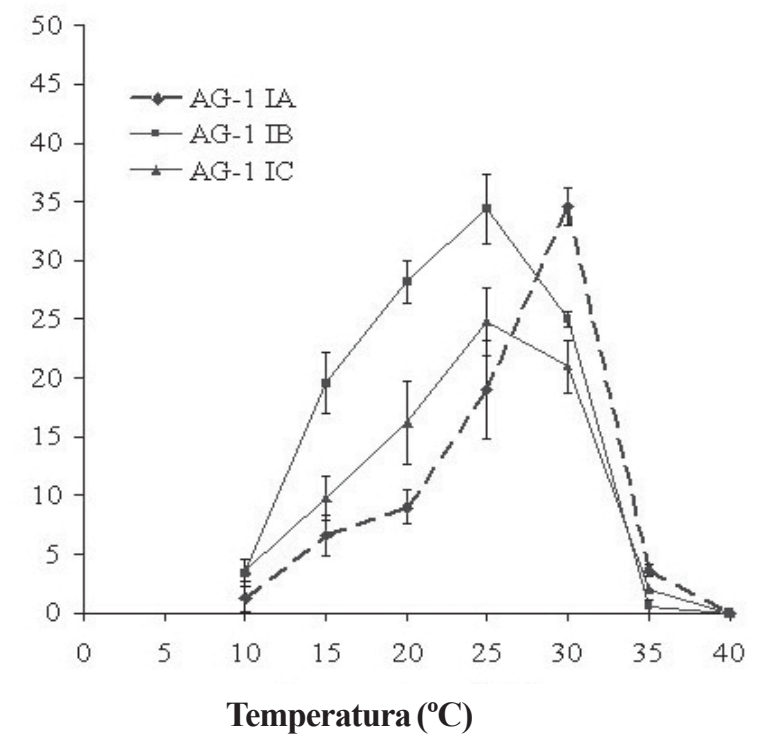

Figura 2. Curvas de crescimento micelial radial ( $\mathrm{mm} / \mathrm{dia})$ de isolados de Rhizoctonia solani do arroz e da soja e de isolados padrões pertencentes aos grupos de anastomose AG-1 IA, IB e IC, em meio de BDACE após 48h de incubação.

*Média de 5 repetições. As barras indicam o desvio padrão da média.

Tabela 2. Temperaturas basais e necessidade de tiamina para crescimento micelial apresentada por isolados padrões de grupos de anastomose Rhizoctonia solani e dos isolados de arroz e soja associados à queima da bainha do arroz ou à mela da soja.

\begin{tabular}{|c|c|c|c|c|c|c|c|c|c|c|}
\hline \multirow[t]{3}{*}{ Isolados ${ }^{1}$} & \multirow{2}{*}{\multicolumn{3}{|c|}{$\begin{array}{c}\text { Temperatura para } \\
\text { crescimento micelial }\left({ }^{\circ} \mathrm{C}\right)\end{array}$}} & \multirow{3}{*}{$\begin{array}{c}\text { TCMR na } \\
\text { temperatura } \\
\text { ótima }^{2} \\
(\mathrm{~mm} / \mathrm{dia})\end{array}$} & \multirow{3}{*}{$\begin{array}{l}\text { Desvio } \\
\text { padrão }\end{array}$} & \multicolumn{5}{|c|}{ Massa seca de micélio (mg) ${ }^{3}$} \\
\hline & & & & & & \multirow{2}{*}{$\begin{array}{c}\text { Sem } \\
\text { tiamina } \\
(\mathrm{A}) \\
\end{array}$} & \multirow{2}{*}{$\begin{array}{l}\text { Desvio } \\
\text { padrão }\end{array}$} & \multirow{2}{*}{$\begin{array}{c}\text { Com } \\
\text { tiamina } \\
\text { (B) } \\
\end{array}$} & \multirow{2}{*}{$\begin{array}{l}\text { Desvio } \\
\text { padrão }\end{array}$} & \multirow{2}{*}{$\mathbf{B} / \mathbf{A}^{4}$} \\
\hline & Mínima & Ótima & Máxima & & & & & & & \\
\hline AG-1 IA & 10 & $25-30$ & 35 & 34,6 & 1,7 & 178,3 & 61,6 & 257,0 & 31,8 & 1,4 \\
\hline AG-1 IB & 10 & 25 & 30 & 34,4 & 2,9 & 32,3 & 15,9 & 40,5 & 11,5 & 1,3 \\
\hline AG-1 IC & 10 & 25 & 35 & 24,8 & 2,9 & 142,8 & 32,4 & 21,0 & 12,9 & 0,1 \\
\hline AG-2-2 IV ${ }^{5}$ & - & - & - & - & - & 60,0 & 0,0 & 1170,0 & 35,1 & 19,5 \\
\hline AG-4 HGI ${ }^{5}$ & - & - & - & - & - & 863,0 & 22,1 & 1106,0 & 0,0 & 1,3 \\
\hline SJ-47 & 15 & $25-30$ & 35 & 40,0 & 0,0 & 58,5 & 34,2 & 38,3 & 16,6 & 0,7 \\
\hline Rhs-4F1 & 15 & 25 & 35 & 39,8 & 0,4 & 59,5 & 41,2 & 24,8 & 5,5 & 0,4 \\
\hline Rhs-9F1 & 15 & 25 & 35 & 45,0 & 0,0 & 62,0 & 4,9 & 103,8 & 5,4 & 1,7 \\
\hline Rhs-3F6 & 15 & 25 & 35 & 45,0 & 0,0 & 791,5 & 82,3 & 750,0 & 8,1 & 0,9 \\
\hline Rhs-3F1 & 15 & 25 & 35 & 45,0 & 0,0 & 712,8 & 34,6 & 746,0 & 5,3 & 1,0 \\
\hline
\end{tabular}

${ }^{1}$ Informação sobre os isolados utilizados está disponível na Tabela 1.

${ }^{2}$ TCMR $=$ taxa de crescimento micelial radial de isolados crescidos em meio de BDACE por $48 \mathrm{~h}$ de incubação. Média de cinco repetições. As curvas de crescimento micelial são apresentadas na Figura 2.

${ }^{3}$ Isolados cultivados em meio de GASP com $\mathrm{pH}$ corrigido para 7 (suplementado ou não com $10^{-5} \mathrm{M}$ de hidrocloreto de tiamina), a $25^{\circ} \mathrm{C}$ por 19 dias, sob ausência de luz. O inóculo foi constituído de um disco de micélio obtido das margens de culturas crescidas em meio de GASP+A a $25^{\circ} \mathrm{C}$ por 10 dias, sob ausência de luz. Massa seca determinada após secagem em estufa a $65^{\circ} \mathrm{C} / 48 \mathrm{~h}$. Média de cinco repetições.

${ }^{4}$ Valores inferiores a 1,5 para a razão B/A são indicativos de que os isolados são autotróficos para tiamina (35).

${ }^{5}$ Isolados não incluídos no teste de temperaturas basais. 
hospedeiro de origem: Poaceae ou Fabaceae) está relacionada, possivelmente, com diferenças na patologia e na biologia de populações de $R$. solani (14). Em arroz, o patógeno é considerado clonal (34), sendo disseminado e infectando plantas através de estruturas assexuadas (escleródios). Já em soja, o patógeno é essencialmente sexuado, infectando a cultura através de basidiósporos (10).

Objetivou-se, também, comparar as características culturais dos isolados obtidos de arroz e de soja em relação aos isolados padrões do AG-1 IA, IB e IC. Em relação à curva de crescimento em função da temperatura, observou-se que os isolados do arroz, o de soja e os isolados padrões AG-1 IA, AG-1 IB e AG-1 IC apresentaram curvas relativamente semelhantes, porém com peculiaridades (Figura 2). No geral, a temperatura ótima para crescimento dos isolados foi de $25^{\circ} \mathrm{C}$, com exceção do isolado SJ-047 e do padrão de anastomose AG-1 IA, cuja temperatura ótima esteve entre 25 e $30^{\circ} \mathrm{C}$ (Figura 2, Tabela 2). A faixa de temperatura ótima para crescimento micelial do isolado padrão AG-1 IA (bem como do isolado de soja, identificado como tal) está de acordo com o relatado na literatura para este grupo de anastomose (36). Entretanto, os isolados de arroz apresentaram menor crescimento relativo a $30^{\circ} \mathrm{C}$. Em comparação com os isolados de $R$. solani do arroz e da soja, todos os isolados padrões apresentaram crescimento micelial relativamente menor na temperatura ótima. A temperatura mínima para crescimento micelial dos isolados de $R$. solani do arroz e de soja foi de $15^{\circ} \mathrm{C}$. Já os isolados padrões AG1 IA, IB e IC cresceram a $10^{\circ} \mathrm{C}$. Considerando a temperatura máxima para crescimento micelial, apenas o isolado AG-1 IB não cresceu a $35^{\circ} \mathrm{C}$.

A caracterização da necessidade de tiamina por isolados de $R$. solani do arroz foi efetuada acrescentando-se ao teste os isolados padrões AG-2-2 IV (auxotrófico) e AG-4 HGI (autotrófico) para tiamina (Tabela 2). Apenas o isolado AG-2-2 IV diferiu dos demais isolados testados, apresentando razão de crescimento no meio com e sem tiamina (B/A) igual a 19,5, em média. Todos os demais isolados, embora diferissem quanto à massa seca de micélio acumulado apresentaram razão de crescimento B/A semelhante, oscilando entre o mínimo de 0,1 até o máximo de 1,7, em média. Valores inferiores ou próximos a 1,5 para a razão $\mathrm{B} / \mathrm{A}$ são indicativos de que os isolados são autotróficos para tiamina (36). De forma geral, constatou-se que os isolados Rhs-3F1, Rhs-3F6, Rhs-4F1, Rhs-9F1 e o isolado de soja SJ047 são autotróficos para tiamina (ou seja crescem independentemente da presença de tiamina) assim como os isolados padrões AG-1 IA, AG-1 IB, AG-1 IC e AG-4 HGI. Já o isolado AG-2.2 IV foi auxotrófico para tiamina.

Objetivou-se, também, determinar a patogenicidade cruzada dos isolados de arroz à soja "IAC-18" (suscetível à mela) e do isolado de soja ao arroz "IRGA-409". Embora a patogenicidade dos isolados de arroz e de soja às respectivas culturas de origem já havia sido determinada previamente por Fenille (12,13) e Prabhu et al. (31), não há informação sobre a patogenicidade cruzada desses isolados. Após 5 dias da inoculação observou-se que os isolados de $R$. solani oriundos de arroz foram também patogênicos à soja, causando sintomas de mela semelhantes aos observados quando a variedade de soja "IAC-18" foi inoculado com o isolado oriundo da soja (Figura 3a). Observou-se, também, que o isolado de soja foi patogênico às plantas de arroz "IRGA-409" (Figura 3b). Estatisticamente, para a variável área foliar doente (AFD), os isolados de arroz proporcionaram índices de doença superiores ao do isolado de soja (SJ-047) quando inoculados em soja "IAC18", enquanto que a testemunha de soja, por sua vez, não apresentou doença (Tabela 3). Já em arroz "IRGA-409", o isolado de soja proporcionou comprimento e área de lesão semelhantes aos observados para os isolados de arroz, sendo não significativo o efeito de tratamentos. As testemunhas de soja e de arroz não apresentaram sintomas da doença. Para a cultura da soja, o isolado de arroz Rhs-3F1 proporcionou o menor acúmulo de matéria seca, enquanto que os demais isolados de arroz e o de soja foram semelhantes entre si. $\mathrm{O}$ efeito de tratamentos foi não significativo para o acúmulo de matéria seca por plantas de arroz.

Qualquer discussão mais profunda para o fato do isolado de soja ter proporcionado menor índice de doença em soja que os isolados de arroz deve ser entendida como especulação, uma vez que apenas um isolado de soja foi utilizado neste teste. Entretanto, entre as explicações plausíveis pode estar o fato deste isolado de soja ser menos agressivo para a soja. Uma outra explicação pode estar relacionada com a perda
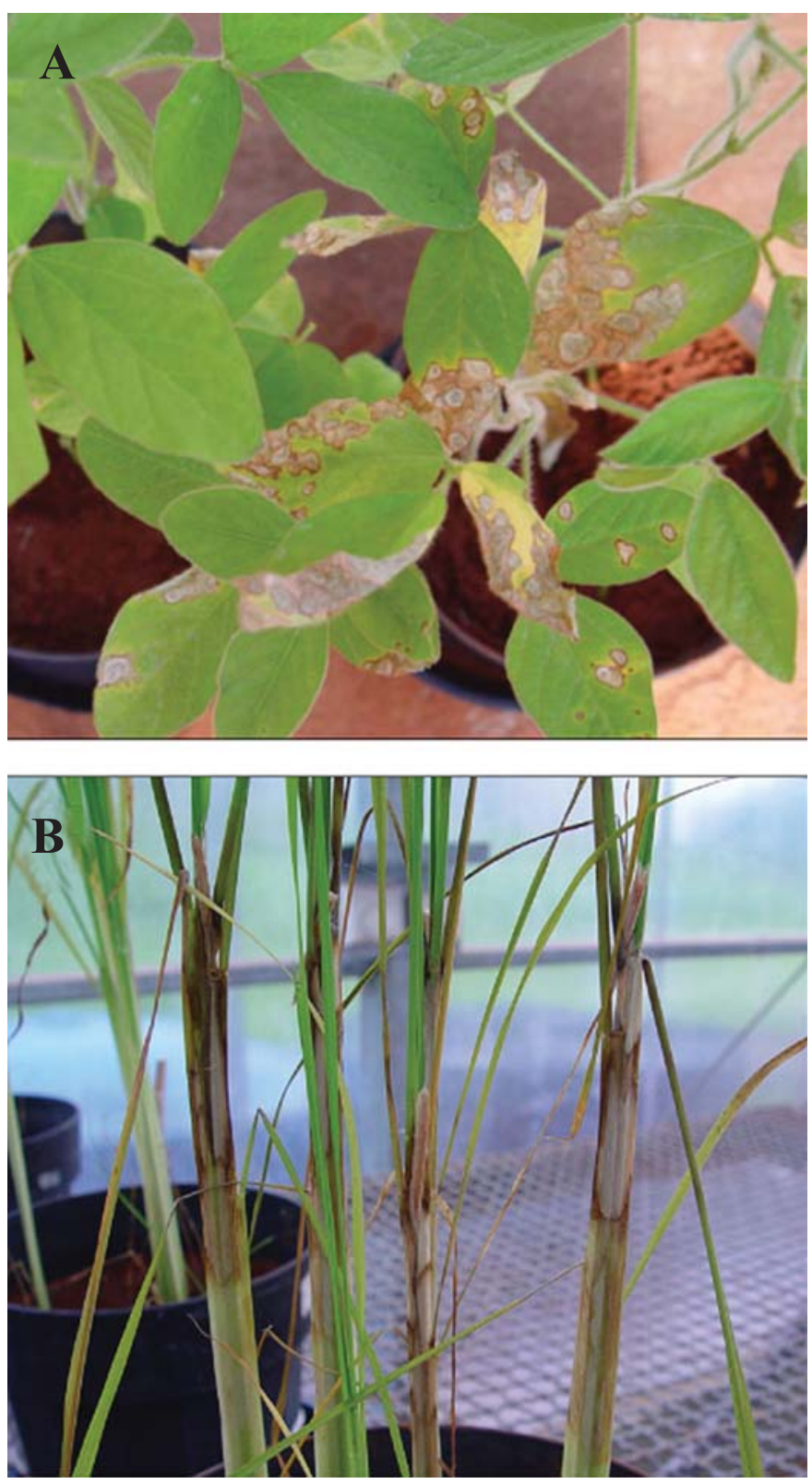

Figura 3. Patogenicidade cruzada de isolados de Rhizoctonia solani AG-1 IA do arroz e da soja, cinco dias após a inoculação. a. Sintomas de mela em plantas de soja "IAC 18" inoculada com o isolado Rhs4F1 de Rhizoctonia solani AG-1 IA do arroz. b. Sintomas de queimada-bainha em plantas de arroz "IRGA-409" inoculado com o isolado SJ-047 de Rhizoctonia solani AG-1 IA da 
Tabela 3. Patogenicidade cruzada de isolados de Rhizoctonia solani do arroz e da soja às plantas de soja cultivar IAC-18 e de arroz da cultivar IRGA-409

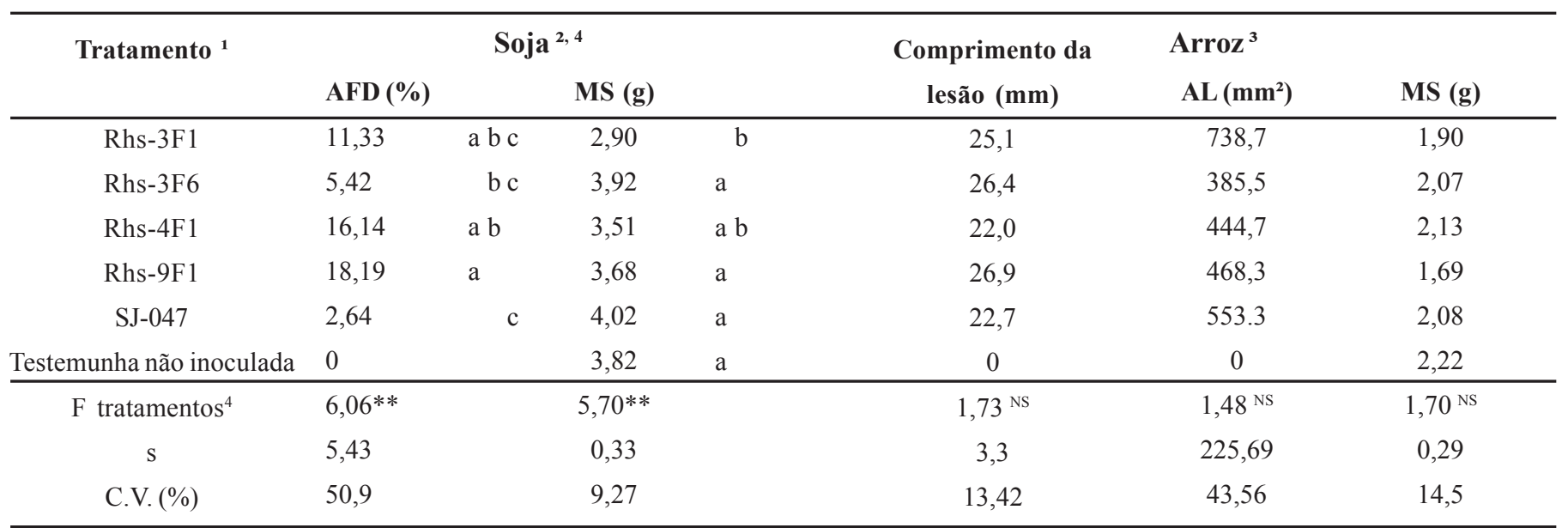

${ }^{1}$ Inóculo preparado cultivando os isolados em meio de BDA + estreptomicina; em soja os isolados foram inoculados através de pulverização de suspensão de micélio e escleródios; em arroz a inoculação foi efetuada através de ferimentos com palito de dente infestado com micélio do patógeno; plantas cultivadas sob condição de casa de vegetação

${ }_{3}^{2}$ Médias da área foliar doente (AFD), e massa seca da parte área (MS) determinada após secagem a $65^{\circ} \mathrm{C} / 48 \mathrm{~h}$.

3 Médias do comprimento da lesão na bainha, área infectada da bainha (AL) e da massa seca da parte área determinada após secagem a $65^{\circ} \mathrm{C} / 48 \mathrm{~h}$ (MS).

${ }^{4}$ Experimento delineado de forma inteiramente casualizada, com 4 repetições Análise de variância através do teste $\mathrm{F}$ de Snedecor; ** significativo a $1 \%$ de probabilidade; ${ }^{\text {NS }}$ não significativo; médias seguidas pela mesma letra (nas colunas) são semelhantes entre si, pelo teste de Tukey a $5 \%$.

de agressividade durante o processo de preservação e multiplicação deste isolado, uma vez que constantes repicagens selecionam para isolados com maior capacidade saprofítica que infectiva (37). Obtido em 1998, este isolado foi introduzido em nossa coleção somente em 2001 e mantido, desde então, em arroz parboilizado congelado a $-20^{\circ} \mathrm{C}$. Toda vez que necessitamos de uma colônia do patógeno, reativamos da cultura mantida a $-20^{\circ} \mathrm{C}$.

Este trabalho traz uma contribuição relativamente simples, através da qual identificou-se isolados de $R$. solani associados ao arroz como pertencentes ao grupo de anastomose AG-1 IA com base em características citomorfológicas, culturais, grupamento filogenético baseado em variação na seqüência da região ITS do rDNA, e patogênese. Os resultados observados no teste de patogenicidade, entretanto são de extrema importância no manejo da doença tanto em arroz quanto em soja, pois as duas culturas são cultivadas em áreas comuns, inviabilizando a rotação arroz-soja (16).

Pesquisas futuras com este patógeno são importantes e devem buscar responder se populações de $R$. solani AG-1 IA de arroz e de soja compartilham os mesmos genótipos do patógeno e se há alguma correlação entre genótipo e agressividade. Com essas informações básicas disponíveis será possível estabelecer/implementar medidas de controle que minimizem a dispersão de genótipos entre populações do patógeno ou para áreas onde a variabilidade genética do patógeno é restrita.

\section{REFERÊNCIAS BIBLIOGRÁFICAS}

1. Adams, G.C. Thanatephorus cucumeris (Rhizoctonia solani), a species complex of wide host range. Advances in Plant Pathology, London, v.6, p.535-552, 1988.

2. Altschul, S.F.; Madden, T.L.; Schäffer, A.A.; Zhang, J.; Zhang, Z.; Miller, W.; Lipman, D.J. Gapped BLAST and PSI-BLAST: a new generation of protein database search programs. Nucleic Acids Research, Oxford, v. 25, p.3389-3402.1997.

3. Amaral, R.E.M.; Issa, E.; Souza, D.M.; Malavolta, V.M.A.; Leite, L.C.; Jesus, L.M. Estudos sobre a queima das bainhas do arroz Oryza sativa L. Arquivos do Instituto Biológico, São Paulo, v.46, p.55-62, 1979.

4. Anderson, N.A. The genetics and pathology of Rhizoctonia solani. Annual Review of Phytopathology, Palo Alto, v.20, p.32974, 1982

5. Balardin, R.S.; Borin, R.S. Doenças na cultura de arroz irrigado. Santa Maria: UFSM. 2001, 48 p.

6. Carling, D.E.; Leiner, R.H. Virulence of isolates of Rhizoctonia solani AG-3 collected from potato plant organs and soil. Plant Disease, St. Paul, v.74, p.901-3, 1990.

7. Carling, D.E.; Kuninaga, S.; Leiner, R.H. Relatedness within and among intraspecific groups of Rhizoctonia solani: A comparison of grouping by anastomosis and by DNA hybridization. Phytoparasitica, Jerusalém, v.16, p.209-10, 1988.

8. Carling. D.E. Anastomosis groups and subsets of anastomosis groups of Rhizoctonia solani. In: INTERNATIONAL SYMPOSIUM ON RHIZOCTONIA, 3, 2000, Taichung. Abstracts... Taichung: International Symposium on Rhizoctonia, 2000. p. 14

9. Ceresini, P.C.; Souza, N.L. Caracterização cultural e fisiológica de Rhizoctonia solani GA4 HGI associado a vagens de amendoinzeiro. Fitopatologia Brasileira, Brasília, v.21, n.4, p. 443-454, 1996.

10. Ciampi, M.B.; Fenille., R.C.; Meyer., M.C.; Souza., N.L.; Kuramae., E.E.; Ceresini., P. C. Intraspecific evolution of Rhizoctonia solani AG-1 IA associated with soybean and rice in Brazil based on polymorphisms at the ITS-5.8S rDNA operon. European Journal of Plant Pathology, Wageningen, v.113, n.2, p.183196, 2005.

11. EMBRAPA. Doenças do arroz e seu controle. Goiânia: EMBRAPA Arroz e Feijão, 2003. Disponível em <http:// www.cnpaf.embrapa.br/tecnolog/dn_queim.htm>. Acesso em 03 Jan 2004.

12. Fenille, R.C. Caracterização citomorfológica, cultural, molecular e patogênica de Rhizoctonia solani Kühn associado à soja no Brasil. Botucatu, 2001. 138p. Tese (Doutorado em Concentração em Proteção de Plantas) - Faculdade de Ciências Agronômicas. Universidade Estadual Paulista "Julio de Mesquita Filho".

13. Fenille, R.C.; Ciampi, M.B.; Kuramae, E.E.; Souza, N.L. Identificação de Rhizoctonia solani associada à soja no Brasil através de seqüências da região $r$ DNA-ITS. Fitopatologia Brasileira, Brasília, v.28, p- 413-419, 2003.

14. Flentje, N.T.; Stretton, H.M. Mechanisms of variation in Thana- 
tephorus cucumeris and T. praticola. Australian Journal Biological Science, Sydney, v.17, p-686-704, 1994.

15. Gordon, D.; Abajian, C.; Green, P. Consed: a graphical tool for sequence finishing. Genome Research, Cold Spring Harbor, v.8, p.195-202, 1998.

16. Groth, D.E.; Nowidk, E.M. Selection for resistance to rice sheath blight through number of infections cushions and lesion type. Plant Disease, St, Paul, v.76, p.721-723, 1992.

17. Groth, D.E.; Rush, M.C.; Hollier, C.A. Prediction of rice sheath blight severity and yield loss based on early season infection. Louisiana Agriculture, Baton Rouge, v.35, p.20-23, 1992.

18. Gonzalez., D.; Carling D.E.; Kuninaga S.; Vilgalys R.; Cubeta M.A. Ribosomal DNA systematics of Ceratobasidium and Thanatephorus with Rhizoctonia anamorphs. Mycologia, Lawrence, v.93, p.1138-1150, 2001

19. Gutierrez. W.A.; Shew. H.D.; Melton. T.A. Sources of inoculum and management for Rhizoctonia solani damping-off on tobacco transplants under greenhouse conditions. Plant Disease, St. Paul, v. 81, p.35, 1998 (Abstract)

20. Herr, L. J.; Roberts, D.L. Characterization of Rhizoctonia solani populations obtained from sugar beet fields with differing soil textures. Phytopathology, St. Paul, v.70, p.476-80, 1980.

21. Kanematsu, S.; Naito, S. Genetic characterization of Rhizoctonia solani AG2-3 by analyzing restriction fragment length polymorphisms of nuclear ribosomal DNA internal transcribed spacers. Annals of the Phytopathological Society of Japan, Tokyo, v 61, p. 18-21, 1995

22. Kuramae-Izioka, E.E. A rapid, easy and high yield protocol for total genomic DNA isolation of Colletotrichum gloeosporioides and Fusarium oxysporum. Revista UNIMAR - Ciências Agrárias, Marilia, v.19, p.683-689, 1997.

23. Liu, Z.; Sinclair, J.B. Genetic diversity of Rhizoctonia solani anastomosis group 2. Phytopathology, St. Paul, v.82, p. 77887,1992 .

24. Liu, Z.; Domier, L.L \& Sinclair, J. B.; ISG-specific ribosomal DNA polymorphism of the Rhizoctonia solani species complex. Mycologia, Lawrence, v.85, p. 795-800, 1993.

25. Matsumoto, T.; Yamamoto, W.; Hirane, S. Physiology and parasitology of the fungi generally referred to as Hypochnus sasakii Shirai. I. Differentiation of the strains by means of hyphal fusion and culture in differential media. Japanese Journal of Tropical Agriculture, Chiba, v.4, p.370-88, 1932.

26. Meyer, M.C. Caracterização de Rhizoctonia solani Kühn. Agente causal da mela da soja [Glycine max (L.) Merril], seleção de genótipos e controle químico. Botucatu. 2002. 125p. Tese (Doutorado em concentração em Proteção de Plantas) - Faculdade de Ciências Agronômicas. Universidade Estadual Paulista " Julio de Mesquita Filho"

27. Ogoshi, A.; Ui, T. Specificity in vitamin requirement among anas- tomosis groups of Rhizoctonia solani Kühn. Annals of the Phytopathological Society of Japan, Tokyo, v.45, p.47-53, 1979.

28. Ogoshi, A. Ecology and pathogenicity of anastomosis and intraspecific groups of Rhizoctonia solani Kühn. Annual Review of Phytopathology, Palo Alto, v.25, p.125-43, 1987.

29. Parmeter, J.R.; Jr., Sherwood, R.T.; Platt, W.D. Anastomosis grouping among isolates of Thanatephorus cucumeris. Phytopathology, St. Paul, v.59, p.1270-8, 1969.

30. Posada, D.; Crandall, K.A. MODELTEST: testing the model of DNA substitution. Bioinformatics, London, v.14, p.817-818, 1998.

31. Prabhu, A.S.; Filippi, M.C.; Silva, G.B.; Santos, G.R. Resistência de cultivares de arroz a Rhizoctonia solani e Rhizoctonia oryzae. Pesquisa Agropecuária Brasileira, Brasília, v. 37, n.5, p.589595, 2002.

32. Prabhu, A.S.; Bedendo, IP.; Filippi, M.C. Principais doenças do arroz no Brasil. Goiânia: EMBRAPA, 1995. Documentos CNPAF, n.2.

33. Ribeiro, A.S. Doenças do arroz irrigado. Pelotas: EMBRAPA. 1984, Circular Técnica UEPAE, n.19.

34. Rosewich, U.L.; Pettway, R.E.; McDonald, B.A.; Kistler, H.C. High levels of gene flow and heterozygote excess characterize Rhizoctonia solani AG-1 IA (Thanatephorus cucumeris) from Texas. Fungal Genetics and Biology, London, v. 28, p.148$159,1999$.

35. Santos, J.R.M.; Galvão, E.U.P. Avaliação de doença em germoplasma de arroz em várzea e terra firme no Amazonas. Pesquisa Agropecuária Brasileira, Brasília, v.24, n.2, p.1483, 1989.

36. Sneh, B.; Burpee, L.; Ogoshi, A. Identification of Rhizoctonia species. Saint Paul: American Phytopathological Society, 1991. $133 \mathrm{p}$.

37. Sneh, B.; Adams. G.C. Culture preservation methods for maintaining genetic integrity of Rhizoctonia ssp. isolates. In: Sneh, B.; Jabaji-Hare, S.; Neate, S.; Dijst, G. ( ed.) Rhizoctonia species: taxonomy, molecular biology, ecology, pathology and disease control. Dordrecht: Kluwer Academic, 1996. p. 139-146.

38. Swofford, D.L. PAUP*. Phylogenetic analysis using parsimony (*and other methods), version 4.0b10. Sunderland: Sinauer Associates, 2002.

39. Webster, R.K.; Gunell, P.S. Compendium of rice diseases. St. Paul: APS, 1992. 62p.

40. Thompson, J. D.; Gibson, T. J.; Plewniak, F.; Jeanmougin, F.; Higgins, D.G. The ClustalX windows interface: flexible strategies for multiple sequence alignment aided by quality analysis tools. Nuclei Acids Research, Oxford, v.25, p.4876-82, 1997.

41. Vilgalys, R.; Cubeta, M.A. Molecular systematics and population biology of Rhizoctonia. Annual Review of Phytopathology, Palo Alto, v. 32, p.135-55, 1994 